\title{
Pentingnya Konsumsi Tempe pada Penderita Diabetes Melitus di Kelompok Ibu-Ibu Senam di Kelurahan Talang Banjar
}

\author{
Iin Indrawati ${ }^{1}$, Maimaznah ${ }^{2}$ \\ ${ }^{1,2}$ Program Studi DIII Keperawatan STIKes Baiturrahim \\ Email : iinian737497@gmail.com
}

Submitted : 11/11/2019

Accepted: 18/11/2019

Published: $31 / 01 / 2020$

\begin{abstract}
People with DM have a risk of experiencing coronary heart disease 3.2 times greater than nonsufferers, the risk of having a stroke 2.9 times greater. Effective and efficient DM management requires effective prevention and mitigation programs. One way to prevent this is to know the characteristics of individuals who are at risk of developing DM. The influence of education on dietary regulation is important for DM sufferers. This community service activity is intended to provide a solution for mothers who suffer from DM to want to consume tempe regularly with a predetermined amount. The method of implementation of the activity used was a health check in the form of checking blood sugar for women who participated in gymnastics as well as screening for DM sufferers. Patients who were netted to have DM were collected and given health education about the importance of eating tempe as an effort to control blood sugar without changing the daily habits that are commonly practiced by DM sufferers in terms of food and drug consumption.Community service activities carried out in the form of health education activities in the form of an invitation to the public to want to consume tempeh regularly with a certain amount every day.The results of community service activities have led to the emergence of new habits in terms of daily food consumption by adding tempe menus to food.
\end{abstract}

Keywords : DM, Tempe

Abstrak

Orang dengan DM memiliki resiko mengalami penyakit jantung coroner 3,2 kali lebih besar dibandingkan non penderita, resiko mengalami stroke 2,9 kali lebih besar. Penanggulangan DM yang efektif dan efisien membutuhkan program pencegahan dan penanggualangan yang tepat sasaran. Salah satu cara mencegahnya adalah dengan mengetahui karakteristik individu yang berisiko mengalami DM. Pengaruh pendidikan tentang pengaturan pola makan merupakan hal penting untuk dilakukan oleh para penderita penyakit DM. Kegiatan pengabdian masyarakat ini ditujukan untuk memberikan solusi bagi ibu-ibu yang menderita penyakit DM untuk mau mengkonsumsi tempe secara teratur dengan jumlah yang telah ditentukan. Adapun metode pelaksanaan kegiatan yang digunakan adalah pemeriksaan kesehatan berupa pengecekan gula darah kepada ibu-ibu peserta senam sekaligus menskrinning penderita DM. Penderita yang terjaring mengalami penyakit DM dikumpulkan dan diberikan pendidikan kesehatan tentang pentingnya makan tempe sebagai upaya untuk mengontrol gula darah tanpa merubah kebiasaan harian yang biasa dilakukan oleh penderita DM dalam hal konsumsi makanan dan obat-obatan. Kegiatan pengabdian masyarakat yang dilakukan berupa kegiatan pemberian pendidikan kesehatan berupa ajakan pada masyarakat untuk mau mengkonsumsi tempe secara teratur dengan jumlah tertentu setiap harinya. Hasil dari kegiatan pengabdian pada masyarakat ini yaitu memunculkan kebiasaan baru dalam hal konsumsi makanan harian dengan penambahan menu tempe dalam makanan.

Kata Kunci: DM, tempe

\section{LATAR BELAKANG}

DM di Indonesia telah menjadi masalah kesehatan yang cukup penting. Berdasarkan data epidemiologi diperkirakan bahwa pada tahun 2030 prevalensi diabetes mellitus di Indonesia mencapai 21,3 juta orang. Meningkatnya prevalensi dan terjadinya komplikasi pada orang dengan DM menimbulkan kerugian yang sangat besar baik secara individual, 
maupun sektor kesehatan secara keseluruhan. Biaya perawatan baik langsung maupun tidak langsung pada orang yang hidupdngan DM di yakinilebihbesar dibandingkan dengan orang non DM (Irawan, 2010). Selain itu dampak psikologis yang diakibatkan oleh komplikasi DM juga akan menyebabkan timbulnya masalah-masalah sosial.

Orang dengan DM memiliki resiko mengalami penyakit jantung coroner 3,2 kali lebih besar dibandingkan non penderita, resiko mengalami stroke 2,9 kali lebih besar (CDC, 2003). Selain penyakit kardiovaskuler, DM juga merupakan salah satu penyebab utama penyakit ginjal, kebutaan dan amputasi pada usia dibawah 65 tahun. Dampak lain dari DM adalah mengurangi umur harapan hidup sebesar 5 - 10 tahun (Hill,2011).

Penanggulangan DM yang efektif dan efisien membutuhkan program pencegahan dan penanggualangan yang tepat sasaran. Salah satu cara mencegahnya adalah dengan mengetahui karakteristik individu yang berisiko mengalami DM. Berdasarkan teori terdapat beberapa factor resiko yang berhubungan dengan kejadian DM, yaitu factor sosiodemografi prilaku dan keadaan klinis atau mental individu. Faktor sosiodemografi diantaranya adalah usia, jenis kelamin, pekerjaan, tingkat pendidikan dan status perkawinan. Prilaku atau gaya hidup yang dimaksud adalah kebiasaan makan, merokok dan aktifitas fisik. Sedangkan keadaan klinis atau mental adalah indeks massa tubuh, lingkar perut dan stress. Pengaruh pendidikan tentang pengaturan pola makan merupakan halpenting untuk dilakukan oleh para penderita penyakit DM.

Pada kegiatan pengabdian yang kami lakukan pada kegiatan ini adalah berupa pendidikan kesehatan berupa ajakan untuk mengkonsumsi tempe. Karena seperti diketahui pada penelitian yang dilakukan oleh Indrawati I dan Maimaznah (2018) menunjukkan bahwa ada pengaruh konsumsi tempe terhadap penurunan kadar gula darah dalam tubuh.

Masyarakat Indonesia hampir diseluruh daerahnya mengenal makanan tempe dengan baik, selain itu tempe juga dikenal dengan makanan yang bernilai gizi tinggi, mudah didapat dan harganya juga sangat terjangkau oleh rata-rata ekonomi masyarakat Indonesia. Hal itujuga yang memperkuat keninginan kami untuk memberikan pendidikan kesehatanberupa ajakan untuk mengkonsumsi tempedalam jumlah yang telah ditentukan secara rutin (setiaphari) padapenderita DM tanpakomplikasiasamurat.

Kegiatan pengabdian masyarakat ini akan memberikan Pendidikan kesehatan secara langsung kepada ibu-ibu dikelompok senam lansia di KelurahanTalang Banjar Kecamatan Jambi Timur Kota Jambi.

\section{TARGET DAN LUARAN}

Kegiatan pengabdian masyarakat ini ditujukan pada penderita DM di kelompok ibu-ibu senam kelurahan talang banjar. Kegiatan ditujukan untuk memberikan solusi bagi ibu-ibu yang menderita penyakit DM untuk mau mengkonsumsi tempe secara teratur dengan jumlah yang telah ditentukan. Secara rinci target kegiatan pengabdian ini dapat dilihat pada tabel .1: Tabel. 1 Target Kegiatan Pengabdian

\begin{tabular}{|c|c|c|}
\hline Target & Sebelum & Sesudah \\
\hline Melakukan & Pengurus & Pengurus \\
\hline pendekatan & hanya & bersedia untuk \\
\hline dengan & melakukan & memfasilitasi \\
\hline pengurus & kegiatan & kegiatan \\
\hline kelompok & rutin & pendidikan \\
\hline lansia & senam & kesehatan yang \\
\hline Kelurahan & tanpa ada & direncanakan \\
\hline Talang Banjar & program & dan menyambut \\
\hline & pendidikan & baik kegiatan \\
\hline & kesehatan & tersebut \\
\hline \multirow{7}{*}{$\begin{array}{l}\text { Melakukan } \\
\text { pengkajian } \\
\text { terhadap ibu- } \\
\text { ibu di kelompok } \\
\text { senam lansia. }\end{array}$} & Belum & Dilakukan \\
\hline & pernah & pengkajian \\
\hline & dilakuan & kondisi \\
\hline & pengkajian & kesehatan \\
\hline & untuk & ibu-ibu \\
\hline & menge & datang \\
\hline & $\mathrm{i}$ & lansia \\
\hline
\end{tabular}




\begin{tabular}{|c|c|c|}
\hline & $\begin{array}{l}\text { kesehatan } \\
\text { ibu-ibu }\end{array}$ & perindividu \\
\hline $\begin{array}{l}\text { Melakukan } \\
\text { kegiatan } \\
\text { pengabdian } \\
\text { masyarakat } \\
\text { berupa } \\
\text { penyuluhan/pen } \\
\text { didikan } \\
\text { kesehatan }\end{array}$ & $\begin{array}{l}\text { Belum } \\
\text { dilakukan }\end{array}$ & $\begin{array}{l}\text { Dilaksanakan } \\
\text { pendidikan } \\
\text { kesehatan } \\
\text { penyuluhan. }\end{array}$ \\
\hline $\begin{array}{l}\text { Evaluasi } \\
\text { terhadap } \\
\text { pemahaman dan } \\
\text { keinginan ibu- } \\
\text { ibu penderita } \\
\text { DM untuk } \\
\text { mengikuti yang } \\
\text { anjuran yan } \\
\text { disampaikan }\end{array}$ & $\begin{array}{l}\text { Belum } \\
\text { dilakukan }\end{array}$ & $\begin{array}{l}\text { Dilakukan } \\
\text { evaluasi kondisi } \\
\text { kesehatan } \\
\text { setelah } \\
\text { dilakukan } \\
\text { penyuluhan } \\
\text { setiap } \\
\text { minggunya } \\
\text { selama3 } \\
\text { minggu. }\end{array}$ \\
\hline
\end{tabular}

\section{METODE PELAKSANAAN}

1. Waktu dan Tempat

Kegiatan ini dilaksanakan dalam kurun waktu 4 bulan yaitu dimulai pada bulan Oktober 2017 dan berakhir pada bulan Januari 2018. Di Kelompok ibu-ibu senam kelurahan Talang Banjar. Kota Jambi.

2. Tujuan

Tujuan dari kegiatan ini yaitu :

a. Memberikan informasi tentang nilai gizi yang terkandung pada bahan pangan tempe serta khasiat/manfaatnya dalam pengaturan kadar gula darah dalan tubuh.

b. Ibu-ibu anggota kelompok senam dapat mentransformasikan informasi yang didapatnya kepada orang-orang disekitar mereka terutama para penderita DM lainnya untuk mau mengkonsumsi tempe dengan jumlah dan cara pengolahan yang tepat sesuai dengan pengetahuan yang telah diberikan.

\section{Sasaran}

Sasaran dalam kegiatan ini adalah ibu-ibu kelompok senam khususnya para penderita DM di Kelurahan Talang banjar yang berjumlah 120 orang.

4. Kontribusi peserta pengabdian

Kontribusi sasaran pada kegiatan ini adalah :

a. Menjadi peserta kegiatan pengabdian

b. Mengikuti seluruh proses kegiatan pengabdian

c. Menjadi transformator bagi ibuibu lainnya terutama yang menderita DM agar mau mengkonsumsi tempe sesuai dengan yang dianjurkan.

5. Pelaksanaan kegiatan pengabdian

Tahapan pelaksanaan kegiatan ini dibagi menjadi dua tahap yaitu :

a. Tahap persiapan

1) Bertemu dengan pihak pengurus kelompok senam

2) Perumusan bentuk kegiatan

3) Pembuatan jadwal kegiatan

b. Tahap pelaksana

1) Melaksanakan kegiatan

2) Melakukan evaluasi kegiatan

3) Pembuatan laporan

4) Publikasi

\section{HASIL DAN PEMBAHASAN}

Kegiatan Pengabdian masyarakat ini berusaha untuk memberi informasi tentang alternatif terapi pada ibu-ibu khususnya yang mempunyai resiko dan sudah terkena penyakit Diabetes Mellitus (DM) dalam mngatur pola makan sehat tanpa membatasi atau merubah kebiasaan makan secara ketat/ekstrim. Keuntungan yang akan didapatkan oleh ibu-ibu yang menjadi peserta kegiatan ini adalah menambah kemampuan dirinya dalam meningkatkan kemampuan mengatur pola makan yang lebih sehata dan sesuai dengan kondisi kesehatannya.

Adapun secara rinci kegiatan yang telah dilakukan dapat diuraikan sebagai berikut : 
1. Melakukan pendekatan dengan pengurus kelompok lansia di KelurahanTalang Banjar

2. Melakukan pengkajian terhadap ibuibu di kelompok senam lansia.

3. Melakukan kegiatan pengabdian masyarakat berupa penyuluhan/pendidikan kesehatan

4. Melakukan evaluasi terhadap pemahaman ibu-ibu

5. Membuat laporan kegiatan dan melaporkannya kepada pihak yang terlibat

6. Mempublikasikan hasil kegiatan kejurnal pengabdian masyarakat.

\section{KESIMPULAN DAN SARAN}

\section{Kesimpulan}

Kegiatan Pengabdian masyarakat yang telah dilakukan secara keseluruhan dapat disampaikan dalam kesimpulan berikut ini :

a. Dilakukannya pendekatan dan diskusi dengan pihak pengurus kelompok senam lansia di kelurahanTalang Banjar Kota Jambi untuk menentukan bentuk, waktu, lokasi kegiatan yang akan dilakukan

b. Dilakukannya pengkajianuntuk mengetahui masalahkesehatan dan kaitannya dengan penyakit Diabetes Mellitus.

c. Kegiatan yang dilakukan berupa tindakan langsung melakukan pengkajian dan pemeriksaan fisik.

d. Melakukan evaluasi setelah kegiatan dilakukan berupa tes lisan untuk mengetahui sejauh mana pemahaman ibu-ibu terhadap materi yang telah disampaikan.

e. Membuat rencana tindak lanjut.

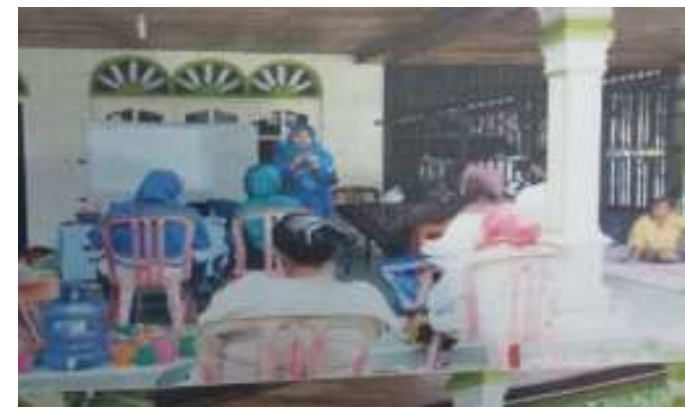

Gambar1. Kegiatan penyuluhan

2. Saran

Setelah memperhatikan dan mengevaluasi hasil dari kegiatan secara keseluruhan maka dapat disarankan kepeada pengurus gan masyarakat (ibu-ibu peserta kegiatan) agar :

1. Terus melakukan konsumsi tempe secara teratur dan memantau kemungkinan adanya efek negatif.

2. Mengatur pola makan yang sehat sebagai salah satu terapi paling baik untuk menjaga kesehatannya.

3. Mengevaluasi secara kontinu perkembangan kondisi kesehatan terutana mengontro kadar gula darah.

\section{UCAPAN TERIMA KASIH}

Terimakasih kepada sekolah tinggi ilmu kesehatan baiturrahim dan pengurus kelompok senam ibu-ibu dikelurahan talang banjar kota jambi yang telah memberikan dana, kesempatan dan mau memfasilitasi kegiatan pengabdian kepada masyarakat ini. Ucapan ini juga ditujukan pada seluruh anggota senam yang telah mau ikut berpartisipasi sehingga kegiatan ini dapat sukses sesuai dengan yang diharapkan.

\section{DAFTAR PUSTAKA}

Astawan, M. (2008). Sehat dengan Tempe. Bogor: Dian Rakyat. ISBN: 979-523932-5

Astawan, M., Resdiyati, T., dan Maknun, L. (2017). Tempe: Sumber zat gizi dan komponen bioaktif untuk kesehatan. Bogor, IPB Press 
Citerawati, Y. W. (2017). asesmen gizi tingkat lanjut. yogyakarta: transmedika

Harrison. (2013). Endokrinologi dan Metabolisme. Alih Bahasa Hartono, A. Tangerang Selatan: KARISMA Publishing Grup

Lemone, P., Burke, K.M., dan Bauldoff, G. (2016). Buku Ajar Keperawatan Medikal Bedah: Gangguan Endokrin, Edisi 5. Alih Bahasa: Angelina, B., dkk.Jakarta: EGC

Robinson, J.M., dan Saputra, L. (2014). Buku Ajar : Visual Nursing (MedikalBedah). Sebuah Panduan Diagnosis Penyakit, Keterampilan, Serta Asuhan Keperawatan. Jilid 2. Alih Bahasa Ardiaria, M. Tangerang: Binarupa Aksara.
Saputra, L. (2014). Ilustrasi Bewarna Patofisiologi Penyakit untuk Perawat, Bidan, dan Paramedis. alih bahasa Esrada, R. tangerang selatan: Binarupa Aksara Publisher. ISBN 978-602-200-172-0

Utari, D.M., Rimbawan., Riyadi, H., Muhilal., dan Purwantyastuti. (2011). Potensi Asam Amino pada Tempe untuk Memperbaiki Profil Lipid dan Diabetes Mellitus. Jurnal Kesehatan Masyarakat Nasional, Vol 5, No.4.

Yulianto, W., A. (2018). pangan fungsional untuk kesehatan otak, jantung, gigi dan mulut, tulang, dan diet untuk diabetes, pelangsing tubuh, penecegahan kanker dan HIV. yogyakarta: CV Budi Utama 